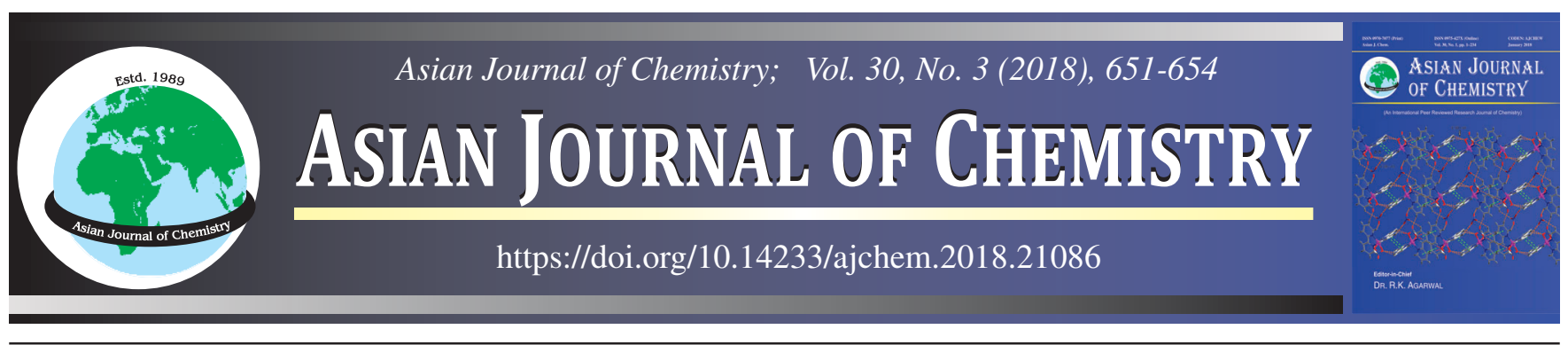

\title{
An Efficient Conversion of Alcohols to Alkyl Bromides Using Pyridinium Based Ionic Liquids: A Green Alternative to Appel Reaction
}

\author{
Pranab J. Das*, Jupitara Das and Dimpee Das
}

Department of Chemistry, Gauhati University, Guwahati-781 014, India

*Corresponding author: E-mail: pranabjdas52@gmail.com

Received: 10 October 2017;

Accepted: 8 January 2018;

Published online: 31 January 2018;

AJC-18760

Pyridinium based ionic liquids namely 4-alkylpyridinium bromides were prepared and used for the conversion of alcohols to alkyl bromides in the presence of $p$-toluenesulphonic acid in the absence of volatile organic compounds. This solvent free procedure promises to be a much improved and environmentally benign alternative to the Appel reaction.

|

Keywords: Appel reaction, Ionic liquid, Solvent free synthesis, Alkylbromides, Aliphatic alcohol.

\section{INTRODUCTION}

Alkyl halides are widely used as industrial solvents and also as essential precursors for the preparation of a variety of fine chemicals. The classical procedure for the conversion of alcohols to alkyl haides is termed as the Appel reaction and in the classical example requires the use of $\mathrm{NaBr}$ and $\mathrm{H}_{2} \mathrm{SO}_{4}$ under harsh reaction conditions [1]. Being and environmentally unacceptable process, this synthesis has limited synthetic applicability today. A direct conversion of alcohols to alkyl halides is difficult due to poor leaving group characteristics of the hydroxyl group, however several improved procedures have been reported to overcome this drawback. An elegant procedure for the conversion was reported wherein triphenylphosphine and tetrahaloalkanes were used [2]. Other notable synthetic procedures are the Mitsunobo reaction [3], the reaction of 2,4,6-trichloro-[1,3,5]-triazine (TCT) in DMF followed by addition of $\mathrm{CH}_{2} \mathrm{Cl}_{2}$ solution of the reactant alcohol [4], the reaction of alcohol with 2,3-trichloro-5,6-dicyanobenzo-quinone in the presence of triphenyl phosphine, $\mathrm{CH}_{2} \mathrm{Cl}_{2}$ and a phase transfer catalyst [5]. ROMP-gel supported triphenyl-phosphine [6], phosphorus (V) mediated nucleophilic substitution reaction [7] and finally the use of fluorous phosphine [8] besides others. The previously reported procedures suffer from the use of toxic and expensive reagents and further the use of triphenylphosphine makes product recovery difficult and time consuming specially due to the in situ formation of the phosphane oxide. In order to avoid the use of triphenylphosphine, an elegant phosphine free halogenation protocol using a visible light photoredox catalyst $\mathrm{Ru}(\mathrm{bpy})_{3} \mathrm{Cl}_{2}$ was reported [9].
The need for environmentally acceptable processes has fuelled great interest towards the use of benign reagents especially the use of ionic liquids to promote reactions. Generally reactions promoted by ionic liquids results in reduced reaction time, simplifies product recovery and greatly improves turn over. Leadbeater et al. [10] used imidazolium based ionic liquids, which played the dual role as a reagent and as a solvent in microwave mediated technique for the conversion of alcohols to the alkyl halides in the presence of mineral acids. Ren and $\mathrm{Wu}$ [11] used 1,3-dimethylimidazolium halide as reagent for the conversion of $n$-butanol and $n$-octanol to the corresponding halide in the presence of bronsted acids such as $\mathrm{HCl}, \mathrm{H}_{2} \mathrm{SO}_{4}$ and $\mathrm{CH}_{3} \mathrm{SOOH}$. Petten et al. [12] used halodehydrogenation technique using ionic liquid for the conversion of long chain alcohols to their respective alkyl halides, Ranu and Jana [13] reported a stereoselective one pot conversion combining the use of ionic liquid and ultrasound and finally a stereoselective one pot conversion of N,N'-diisopropylcarbodiimide was reported [14] besides others $[15,16]$.

\section{EXPERIMENTAL}

GC/MS was carried out on a Perkin Elmer Clarus 600 gas chromatograph and Clarus 600C mass spectrometer (column $30.0 \mathrm{~m} \times 250 \mu \mathrm{m}) .{ }^{1} \mathrm{H}$ was done on a Bruker $300 \mathrm{MHz}$ instrument using $\mathrm{CDCl}_{3}$ as the solvent, 4-methylpyridine, ethylbromide, $n$-butylbromide, $n$-octylbromide, substrate alcohols and $p$-toluenesulphonic acid were purchased from Sigma Aldrich and were used as received. The ionic liquids, 1- $n$-alkyl4-methylpyridinium bromide, were prepared from 4-methylpyridine and characterized. 
Thermogravimetric analysis (TGA): TGA experiments were performed using a TGA-DSC1, Mettler Toledo instrument. The samples were weighed and placed in a platinum crucible. They were then heated in a stream of nitrogen atmosphere, from room temperature to $700{ }^{\circ} \mathrm{C}$ with a heating rate usually of $10^{\circ} \mathrm{C} / \mathrm{min}$.

General method for preparation of ionic liquids: Three different pyridinium based ionic liquids namely 1-ethyl-4methyl pyridinium bromide, 1- $n$-butyl-4-methyl pyridinium bromide and 1-n-octyl-4-methyl pyridinium bromide were prepared by simply mixing 4-methylpyridine ( $\gamma$-picoline) and the appropriate alkyl halide and stirring the mixture in the dark for 20$24 \mathrm{~h}$ (Scheme-I). The yield of the ionic liquids was found to be almost quantitative.

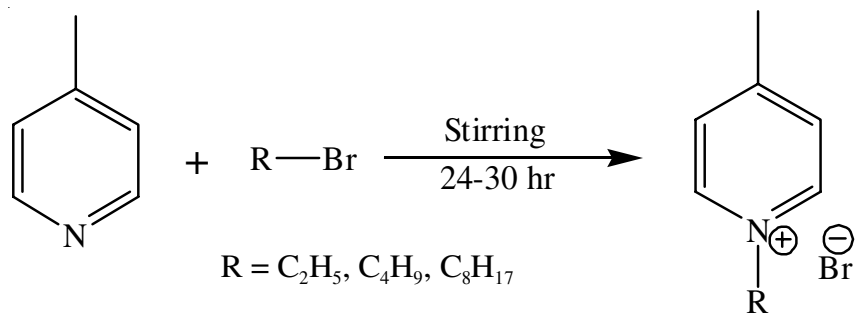

Scheme-I

1-Ethyl-4-methylpyridinium bromide: $m . f .: \mathrm{C}_{8} \mathrm{H}_{12} \mathrm{NBr}$, white solid, melting range $250-300{ }^{\circ} \mathrm{C} ;{ }^{1} \mathrm{H}$ NMR $(300 \mathrm{MHz}$, $\left.\mathrm{CDCl}_{3}, \mathrm{Me}_{4} \mathrm{Si}\right)\left(\delta_{\mathrm{H}} \mathrm{ppm}\right): 9.322(2 \mathrm{H}, \mathrm{d}, J=6.6 \mathrm{~Hz}, \mathrm{pyr}-\mathrm{CH})$, $7.756(2 \mathrm{H}, \mathrm{d}, J=6.3 \mathrm{~Hz}, \mathrm{pyr}-\mathrm{CH}), 4.803(2 \mathrm{H}, \mathrm{q}, J=7.2 \mathrm{~Hz}$, $\left.\mathrm{CH}_{2}\right), 2.503\left(3 \mathrm{H}, \mathrm{s}, \mathrm{CH}_{3}\right), 1.532\left(3 \mathrm{H}, \mathrm{t}, J=7.2 \mathrm{~Hz}, \mathrm{CH}_{3}\right) ;{ }^{13} \mathrm{C}$ NMR $\left(75 \mathrm{MHz}, \mathrm{CDCl}_{3}\right)(\delta \mathrm{ppm}): 158.53,143.85,128.72$, $56.12,22.03,17.03$.

1- $n$-Butyl-4-methyl pyridinium bromide: m.f.: $\mathrm{C}_{10} \mathrm{H}_{16} \mathrm{NBr}$, nature: white waxy solid, melting range $110-280{ }^{\circ} \mathrm{C} ;{ }^{1} \mathrm{H}$ NMR $\left(300 \mathrm{MHz}, \mathrm{CDCl}_{3}, \mathrm{Me}_{4} \mathrm{Si}\right)\left(\delta_{\mathrm{H}} \mathrm{ppm}\right): 9.363(2 \mathrm{H}, \mathrm{d}, J=6.6 \mathrm{~Hz}$, pyr-CH), $7.840(2 \mathrm{H}, \mathrm{d}, J=6.0 \mathrm{~Hz}$, pyr-CH), $4.812(2 \mathrm{H}, \mathrm{t}, J=$ $\left.7.2 \mathrm{~Hz}, \mathrm{CH}_{2}\right), 2.577\left(3 \mathrm{H}, \mathrm{s}, \mathrm{CH}_{3}\right), 1.972-1.872\left(2 \mathrm{H}, \mathrm{m}, \mathrm{CH}_{2}\right)$, $1.381-1.282\left(2 \mathrm{H}, \mathrm{m}, \mathrm{CH}_{2}\right), 0.853\left(3 \mathrm{H}, \mathrm{t}, J=7.2 \mathrm{~Hz}, \mathrm{CH}_{3}\right) ;{ }^{13} \mathrm{C}$ NMR $\left(75 \mathrm{MHz}, \mathrm{CDCl}_{3}\right)(\delta \mathrm{ppm}): 158.51,144.17,128.70$, 60.59, 33.51, 22.08, 19.09, 13.36 .

1- $n$-Octyl-4-methyl pyridinium bromide: m.f.: $\mathrm{C}_{14} \mathrm{H}_{24} \mathrm{NBr}$, nature: light pink waxy solid, melting range $300-400{ }^{\circ} \mathrm{C} ;{ }^{1} \mathrm{H}$ NMR (300 MHz, $\left.\mathrm{CDCl}_{3}, \mathrm{Me}_{4} \mathrm{Si}\right)\left(\delta_{\mathrm{H}} \mathrm{ppm}\right): 9.338(2 \mathrm{H}, \mathrm{d}, J=$ $6.3 \mathrm{~Hz}$, pyr-CH), 7.893 (2H, d, $J=6.3 \mathrm{~Hz}$, pyr-CH), 4.872 $\left(2 \mathrm{H}, \mathrm{t}, J=7.5 \mathrm{~Hz}, \mathrm{CH}_{2}\right), 2.645\left(3 \mathrm{H}, \mathrm{s}, \mathrm{CH}_{3}\right), 2.022-$

$1.941\left(2 \mathrm{H}, \mathrm{m}, \mathrm{CH}_{2}\right), 1.300-1.204\left(10 \mathrm{H}, \mathrm{m}, \mathrm{CH}_{2}\right), 0.824(3 \mathrm{H}$, $\left.\mathrm{t}, J=6.9 \mathrm{~Hz}, \mathrm{CH}_{3}\right) ;{ }^{13} \mathrm{C} \mathrm{NMR}\left(75 \mathrm{MHz}, \mathrm{CDCl}_{3}\right) \delta: 158.54$, $144.11,128.75,60.93,31.69,31.45,28.82,25.84,22.35$, $22.09,13.87$.

General procedure for the conversion: A mixture of 5 mmol alcohol, $5 \mathrm{mmol} p$-toluenesulphonic acid, 5 mmol 1- $n$ butyl-4-methylpyridiniumbromide was heated in an oil bath with constant stirring to different temperatures (Table-2), the progress of the reactions monitored by GC after $0.5,1.0,1.5$, 2.5 and $5 \mathrm{~h}$. In the GC experiments, aliquots of reaction mixture drawn, diluted with $1 \mathrm{~mL}$ of diethylether, solution filtered and GC recorded. After complete conversion as indicated by GC, $25 \mathrm{~mL}$ of $n$-hexane was added to precipitate out the ionic liquid. The filtrate on evaporation of the solvent afforded the bromides, which could be identified by running GC with authentic sample. Products were examined for their purity by TLC using silica gel plates and $n$-hexane:petroleum ether (40-60) (9:1) as the eluent.

Recovery of 1- $n$-butyl-4-methylpyridinium- $p$-toluenesulphonate: After separation of the products, the precipitated ionic liquid was found to be transformed to the $p$-toluenesulphonate. For further purification, $25 \mathrm{~mL}$ petroleum ether $\left(40-60{ }^{\circ} \mathrm{C}\right.$ ) was added to this and stirred for $5 \mathrm{~min}$ to remove any trace of alkyl bromides. The petroleum ether layer on evaporation afforded the 1-n-butyl-4-methyl-pyridinium- $p$ toluenesulphonate, which was recovered and stored in dessiccator. The recovered product was identified as the sulphonate form by ${ }^{1} \mathrm{H}$ NMR spectra. ${ }^{1} \mathrm{H}$ NMR $\left(300 \mathrm{MHz}, \mathrm{CDCl}_{3}\right)$ : $\delta_{\mathrm{H}}$ ppm 8.915 (d, 2H, $J=6.3 \mathrm{~Hz}, \mathrm{ArH}), 7.740-7.685(\mathrm{~m}, 4 \mathrm{H}$, $\mathrm{ArH}), 7.112(\mathrm{~d}, 2 \mathrm{H}, J=7.8 \mathrm{~Hz}, \mathrm{ArH}), 4.612(\mathrm{t}, 2 \mathrm{H}, J=7.2 \mathrm{~Hz}$, $\left.2 \mathrm{H}, \mathrm{NCH}_{2}\right), 2.520$ (s, $\left.3 \mathrm{H}, \mathrm{ArCH}_{3}\right), 2.303$ (s, 3H, $\left.\mathrm{ArCH}_{3}\right), 1.867-$ 1.767 (m, 2H, $\left.\mathrm{CH}_{2}\right), 1.292-1.192\left(\mathrm{~m}, 2 \mathrm{H}, \mathrm{CH}_{2}\right), 0.840$ (t, 3H, $\left.J=7.2 \mathrm{~Hz}, \mathrm{CH}_{3}\right) ;{ }^{13} \mathrm{C} \mathrm{NMR}\left(75 \mathrm{MHz}, \mathrm{CDCl}_{3}\right): \delta \mathrm{ppm} 158.38$, $143.51,139.58,128.50,125.50,60.44,32.94,21.61,20.93$, $18.79,13.10$. The sulphonate form of the ionic liquid was converted to the bromide form by treatment with $30 \% \mathrm{HBr}$.

\section{RESULTS AND DISCUSSION}

In all reported synthetic methods, the imidazolium based ionic liquids were use as the promoter. These ionic liquids are costly, less effective and the methods reported requires high pressure and long reaction time and the procedures are limited to a few selected alcohols and could not be generalized. Search for inexpensive, efficient and environmentally benign methods for carrying out the Appel reaction is still being explored. In order to overcome the disadvantages associated with the use of immidazolium based ionic liquids, we examined the possibility of the use of pyridinium based ionic liquids for promoting the Appel reaction for the conversion of alcohols to the alkyl bromides. The results reported herein indicate the superiority of pyridinium based ionic liquids vis-a-vis imidazolium counterparts. The pyridinium based ionic liquids used in this study were prepared by a simple reported procedure [17] using lowcost and easily available starting compounds. Three different ionic liquids were prepared starting from 4-methylpyridine and corresponding alkyl halides namely 1-ethyl-4-methylpyridiniumbromide [1-E-4-MPyr]Br, 1-n-butyl-4-methyl-pyridinium bromide [1- $n$-B-4Mpyr]Br and 1-n-octyl-methylpyridiniumbromide [1-n-O-4-Mpyr] $\mathrm{Br}$ and characterized. Results indicate that all the ionic liquids have thermal stability upto $250{ }^{\circ} \mathrm{C}$. Thermogravimetric curves of the three ionic liquids indicate that 1- $n$-butyl-4-methyl pyridinium-bromide had a melting range of $110-280{ }^{\circ} \mathrm{C}$ and this being close to the melting range of usual ionic liquids was considered to be the most appropriate of the three ionic liquids for the present synthesis. The TGA curves are shown in Fig. 1.

The ionic liquids were used as a promoter for a solvent free conversion of a variety of alcohols to the corresponding bromides. Initially the efficiency of the individual ionic liquids were screened for their utility. The conversion of octan-1-ol to 1-bromooctane using the three ionic liquids individually was examined as a model reaction and the results summarized 

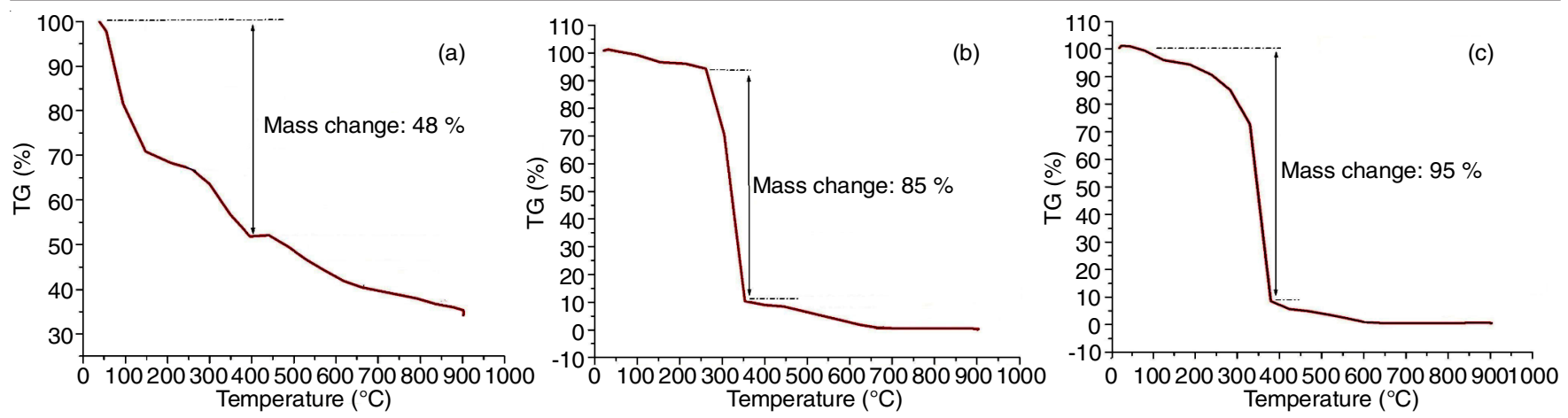

Fig. 1. TGA curve of (a) 1-n-butyl-4-methylpyridiniumbromide (b) 1-ethylpyridiniumbromide (c) 1-n-octylpyridiniumbromide

in Table-1. Results indicates the better efficiency, in terms of better yield of products, of 1- $n$-butyl-4-methyl-pyridiniumbromide [1-n-B-4Mpyr]Br over other ionic liquids used. Consequently all subsequent reactions were carried out with using [1- $n$-B4Mpyr]Br.

\begin{tabular}{cccc}
\multicolumn{5}{c}{ TABLE-1 } \\
EFFICIENCY OF DIFFERENT PYRIDINIUM BASED \\
IONIC LIQUID FOR CONVERSION OF OCTAN-1-OL TO \\
$n$-OCTYLBROMIDE AFTER 5 h OF REACTION TIME
\end{tabular}

In a typical procedure, an equimolar mixture of alcohol, $p$-toluenesulphonic acid and 1- $n$-butyl-4-methylpyridiniumbromide was taken in an round bottom flask and heated to the optimized temperature for range of reaction time. The progress of the reaction was monitored by GC of aliquots drawn from the reaction mixture at time intervals of $0.5,1.5,2.5$ and $5 \mathrm{~h}$. The reaction is shown in Scheme-II and results obtained for a variety of alcohols summarized in Table-2. The reaction time and temperature necessary for complete conversion, varied with the nature of the substrate alcohol.

\section{Conclusion}

The use of pyridinium based ionic liquid for the Appel reaction offers an easy access to the alkylbromides. The products could be isolated by simple filtration of the precipitated ionic liquids. The precuts were identified performing GC with authentic sample. The ionic liquids could be recycled. Simple reaction condition, absence of costly reagents, high turnover of products makes this procedure an improved practical alternative to the conventional Appel reaction.

\section{ACKNOWLEDGEMENTS}

One of the author, JD is grateful to CSIR, New Delhi for grant of Junior Research Fellowship and another author, DD is grateful to University Grand Commission, New Dehi for providing the fellowship under BSR programme.

\begin{tabular}{|c|c|c|c|c|c|}
\hline \multicolumn{6}{|c|}{$\begin{array}{l}\text { TABLE-2 } \\
\text { SYNTHESIS OF ALKYL BROMIDES FROM ALCOHOLS USING AS THE } \\
\text { IONIC LIQUID [1-B-4-M-Pyr]Br AS THE BROMINATING AGENT }\end{array}$} \\
\hline Entry & Reactants & Products & Reaction temp. $\left({ }^{\circ} \mathrm{C}\right)$ & Time (h) & Conversion $(\%)$ \\
\hline 1 & Butan-1-ol & $n$-Bromobutane & 100 & 5.0 & 100 \\
\hline 2 & Pentan-1-ol & $n$-Bromopentane & 130 & 5.0 & 100 \\
\hline 3 & Pent-2-ol & 2-Bromopentane & 120 & 7.0 & 100 \\
\hline 4 & Hexan-1-ol & $n$-Bromohexane & 130 & 4.0 & 100 \\
\hline 5 & Cyclohexanol & Bromocyclohexane & 140 & 5.0 & 100 \\
\hline 6 & Heptan-1-ol & $n$-Bromoheptane & 130 & 5.0 & 100 \\
\hline 7 & Octan-1-ol & $n$-Bromooctane & 140 & 2.5 & 100 \\
\hline 8 & Benzyl alcohol & Benzyl Bromide & 140 & 0.5 & 100 \\
\hline 9 & 4-chlorobenzyl alcohol & 4-Chlorobenzyl Bromide & 140 & 1.0 & 100 \\
\hline
\end{tabular}

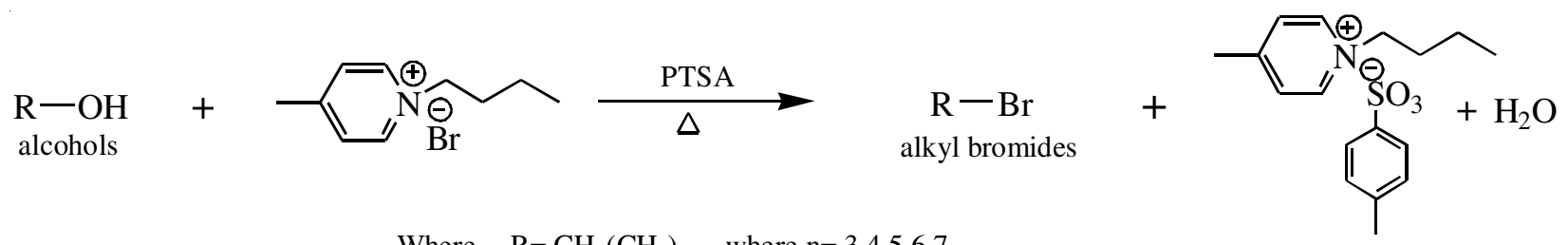

Where $\mathrm{R}=\mathrm{CH}_{3}\left(\mathrm{CH}_{2}\right)_{\mathrm{n}^{-}} \quad$ where $\mathrm{n}=3,4,5,6,7$

$$
=\mathrm{C}_{6} \mathrm{H}_{11}, \mathrm{C}_{6} \mathrm{H}_{5} \mathrm{CH}_{2}, 4-\mathrm{ClC}_{6} \mathrm{H}_{4} \mathrm{CH}_{2-}
$$

Scheme-II: Conversion of alcohols to alkylbromides using pyridinium based ionic liquids 


\section{REFERENCES}

1. J.R. Nohring, C.N. Hammond, C.N. Morrill and D.C. Neckers, Experimental Organic Chemistry, W.H. Freeman and Co., NY (1998).

2. R. Appel, R. Kleinstueck and K.D. Ziehn, Angew Chem. Int. Ed. Engl. 10, 132 (1971) https://doi.org/10.1002/anie.197101321.

3. O. Mitsunobu, Synthesis, 1 (1981); https://doi.org/10.1055/s-1981-29317.

4. L. De Luca, G. Giacomelli and A. Porcheddu, Org. Lett., 4, 553 (2002); https://doi.org/10.1021/ol017168p.

5. R. Ling, M. Yoshida and P.S. Mariano, J. Org. Chem., 61, 4439 (1996); https://doi.org/10.1021/j0960316i.

6. E. Arstad, A.G.M. Barrett, B.T. Hopkins and J. Köbberling, Org. Lett., 4, 1975 (2002) https://doi.org/10.1021/o1026008q.

7. R.M. Denton, J. An, B. Adeniran, A.J. Blake, W. Lewis and A.M. Poulton, J. Org. Chem., 76, 6749 (2011); https://doi.org/10.1021/jo201085r.

8. L. Desmaris, N. Percina, L. Cottier and D. Sinou, Tetrahedron Lett., 44, 7589 (2003);

https://doi.org/10.1016/j.tetlet.2003.08.064.
9. J.M.R. Narayanam, J.W. Tucker and C.R.J. Stephenson, J. Am. Chem. Soc., 131, 8756 (2009); https://doi.org/10.1021/ja9033582.

10. N.E. Leadbeater, H.M. Torenius and H. Tye, Tetrahedron, 59, 2253 (2003); https://doi.org/10.1016/S0040-4020(03)00214-X.

11. R.X. Ren and J.X. Wu, Org. Lett., 3, 3727 (2001); https://doi.org/10.1021/o1016672r.

12. C.F. Petten, H.A. Kalviri and F.M. Kerton, Sustain. Chem. Process., 3, 16 (2015);

https://doi.org/10.1186/s40508-015-0043-4.

13. B.C. Ranu and R. Jana, Eur. J. Org. Chem., 755 (2005); https://doi.org/10.1002/ejoc.200400597.

14. S. Crosignani, B. Nadal, Z. Li and B. Linclau, Chem. Commun., 21, 260 (2003); https://doi.org/10.1039/b211424k.

15. S.G. Newman, C.S. Bryan, D. Perez and M. Lautens, Synthesis, 342 (2001); https://doi.org/10.1055/s-0030-1258368.

16. P. Verdía, E.J. González, B. Rodríguez-Cabo and E. Tojo, Green Chem., 13, 2768 (2011); https://doi.org/10.1039/c1 gc15408g.

17. A. Aupoix, B. Pe'got and G. Vo-Thanh, Tetrahedron, 66, 1352 (2010); https://doi.org/10.1016/j.tet.2009.11.110. 